\title{
Magnitude of Interaction between Language of Instruction of Prior Education and Learning Traits on Academic Achievement Scores of International Students
}

\author{
Dr. Varughese Kuzhumannil Varughese (corresponding author) \\ School of Life and Physical Sciences, College of Science, Engineering and Health \\ RMIT University, Melbourne, Australia \\ Tel: 61-3-9925-8378 Fax: 61-3-9925- $4144 \quad$ E-mail: varughese.varughese@rmit.edu.au \\ Assoc. Prof. Heather Fehring \\ Deputy Head Research \& Innovation \\ School of Education, College of Design \& Social Context \\ RMIT University, Melbourne, Australia \\ Tel: 61- 3-9925-7840 Fax: 61-3-9925-7184Ｅ-mail: heather.fehring@rmit.edu.au
}

\begin{abstract}
This paper investigates the magnitude of difference of academic achievement scores by language of instruction of prior education and the magnitude of interaction between language of instruction of prior education and students' preferred learning trait on academic performance of a group of international students in two teaching and learning practices. The magnitude of difference and magnitude of interaction were determined by using Cohen's $d$ with Hedges $g$ correction. Coe's spread sheet was used for the analysis. The study showed that the magnitude of difference of academic achievement score was found to be very small on Traditional method of Teaching and Learning (TTL) and small on Problem-Based method of Learning (PBL). However, the magnitude of interaction between language of instruction of prior education and learning traits varied from very small to large. It is a challenging task to accommodate international students from different language background and optimize the whole learning process in an English speaking teaching and learning environment.
\end{abstract}

Keywords: International Students, Learning Traits, Effect Size, Magnitude of Differences, Teaching \& Learning Practices.

\section{Introduction}

The study investigated the magnitude of difference of academic achievement by language of instruction of prior education and the magnitude of interaction between the language of instruction of prior education and students' learning trait on academic achievement under two methods of teaching and learning practices. The participants of this study were international Biology students in Foundation Studies (FS) at the Royal Melbourne Institute of Technology (RMIT) University, Australia. These students were from different cultural, social, educational and linguistic backgrounds. Researches have supported the fact that students from different cultures tend to exhibit greater diversity in their approaches to learning than students from relatively same or similar cultures (Bennett, 1999). The purpose of this study was two fold. Firstly, to find whether there was any effect of language of instruction of prior education on their academic performance under two different methods of teaching and learning and secondly, what was the magnitude of interaction between language of instruction of prior education and learning traits on academic achievement scores. It is a challenging task to accommodate all individual differences, optimise the learning environment and engage and support students together effectively (Felder, 1993). The two methods used in this study were the Traditional Teaching and Learning (TTL) and Problem-Based learning (PBL). It is well established that students' individual differences influence both their learning and their academic achievement (Riding, 2005). A study conducted at the RMIT University showed that the magnitude of differences in performance by students' approaches to learning in two pedagogical environments varied from small to medium (Varughese \& Fehring, 2009). However, no study has measured the magnitude of interaction between language of instruction of prior education and students' learning trait on academic achievement scores under TTL and PBL. It is on this count that this study is unique and differs from other educational research in this field. 
Science education is concerned with imparting scientific knowledge and skills to individuals who are not part of the scientific community. These individuals may be school children, college students or adults within the general public. The field of science education comprises science content, some sociology and some teaching pedagogy (Fraser \& Tobin, 2001). Research in science education emphasises the metalearning of the learning community. This piece of research throws some light on the metalearning of students with diverse language background. The FS at RMIT is a pathway for international students to their higher education at RMIT or any other higher institution in Australia (RMIT, 2006). The program extends over two semesters and students who are doing biology have various options in their future education include medicine, nursing, physiotherapy, chiropractic, pharmacy, food technology, environmental sciences and biological sciences. Health education in Australian universities is increasingly using the Problem-Based method of teaching and learning. It is in this context that this study seeks to examine whether International students from vastly different educational, cultural and linguistic backgrounds are able to learn successfully under the PBL method. An important feature of PBL is that it is a student-centred approach of learning. In this method students learn to determine what they need to know. PBL is an instructional method that challenges students to learn how to learn, work cooperatively in groups to seek solutions to real world problems (Duch \& Norton, 1992). Students in FS are encouraged to develop both a deep and achieving approach in their learning. In order to pursue their further studies in tertiary education, they have to develop deep understanding in their learning areas and at the same tine they have to get the required study scores to get admission in their field of interest after FS.

\section{Research Participants}

The participants of this research were all international students from FS at RMIT over a period of four academic years. All the participants were offered Biology along with four other courses of which English was compulsory. There were two intakes in each year with an average of 14 Biology students in each intake. The first intake designated as Group 1 runs from January to November consisting of two 18-week semesters with five contact hours per week for Biology. The first semester for this intake runs from February to June and the second semester from July to November each year. The second intake designated as Group 2 runs from June to January and consists of two 14-week semesters with six contact hours per week. The first semester for the second intake runs from June to September and the second semester from October to January of the following year.

\section{Data collection}

The data collection commenced after obtaining the ethics approval from Human Research Ethics Sub Committee (HRESC) of RMIT. It was conducted in the second semester for both Groups 1 and 2 of each academic year. Students' name, student number and nationality were collected by using a simple questionnaire. Name and student number were included in the questionnaire to identify each student at any time during the course of the research. The nationality was included to determine students' heterogeneity in terms of their cultural background.

Of the ten topics in semester 2, one topic (Topic 1) was taught under the TTL method and the second topic (Topic 2) was taught under PBL method for the intake one (Group 1) of each year. For the intake two (Group 2) of each year, Topic 1 was taught under PBL method and Topic 2 was taught under TTL method. At the end of each topic a test was conducted to assess students' understanding in these particular areas. The test that was given after TTL method of teaching was named TTL test and the test after the PBL method of teaching was called the PBL test for the analysis purpose. Thus each participant took both TTL and PBL tests. Each test consisted of two sections, Section A and Section B. Section A of each test consisted of 20 multiple-choice questions worth 20 marks. Section B of both tests consisted of four short questions worth 10 marks each. Hence the total mark for each test was 60 .

The Paragon Learning Style Inventory (PLSI), was used to assess students' preferred learning traits (Shindler, 2002). The permission for using this inventory was obtained from the director of Paragon Educational Consulting. The PLSI is a self-administered inventory based on the personality test called MBTI, which in turn is based on Jung's theory of personality (Yeung, Read, \& Schmid, 2005). It was developed specifically for use in educational settings in determining the learning styles (Yeung \& Read, 2006). Most of the FS students have difficulties in the usage of English language. Hence it was decided to use PLSI because of its simple language and structure of questions in determining students learning traits. The PLSI uses Jungian/Myers-Briggs dimensions, Extroversion/Introversion, Sensing/Intuiting, Thinking/Feeling and Judging/Perceiving. Sixteen Learning Style categories are formed from these dimensions. However, because of the fewer participants in this research, it may not be possible to derive conclusive results when there are very few students in some of the learning style categories. Hence the learning style category has been considered as the variable defined by the 
four dimensions for all analysis purposes. Each dimension has two traits and each student has one or the other as a preferred trait. It provides a much better distribution of the participants over four learning traits, lending greater credibility to any result analysis.

\section{Data Analysis}

The analyses were mainly carried out using the statistical package SPSS 13.0 and an Excel spreadsheet. The study investigated the magnitude of difference of academic achievement by the language of instruction of prior education and the magnitude of interaction between language of instruction of prior education and students' learning trait on academic achievement under two methods of teaching and learning practices. A format was set up for data entry and it captured the information such as number of students who had English and languages other than English as the language of instruction for their prior qualifications, TTL test marks, PBL test marks and number of students in each learning trait. Various functions of SPSS and Excel were used to ensure that all data had been correctly entered and then preliminary analysis of data was carried out. Frequency tables for the variables were used to check for any missing values or errors as well as to obtain appropriate frequency distributions of the data. Having completed the preliminary analysis of comparisons the data were then analysed to investigate variations and effects of these variations. This was carried out using effect size analysis. The appropriate statistics for educational research are point estimates of sizes and confidence intervals around these point estimates. Substantive significance is more useful than statistical significance. When a teaching method is compared with another method, the magnitude of the difference between the methods may not be large enough to be worth the expense of changing methods. Effect sizes were calculated by using Cohen's d (Cohen, 1988) with Hedges g correction (Hedges \& Olkin, 1985). Coe's spreadsheet (Coe, 2006) was used for the purpose. Hedges's $g$ is an inferential measure and is calculated by using the square root of the mean square error from the analysis of variance testing for differences between the two groups (Hedges \& Olkin, 1985). Effect size measures the treatment effect (Glass, McGaw, \& Smith, 1981). Descriptors for magnitudes of effect sizes include small, medium, large (Cohen, 1969) and very small (Izard, 2004). An effect size of $\geq 0.8$ has been classified as large, any value $\geq 0.5$ and $<0.8$ as medium, a value $\geq 0.2$ and $<0.5$ as small, and anything $<0.2$ as very small or negligible. In effect this provides an assigned range on either side of the endpoints for decimal rounding. For example any effect size from 0.45 to 0.74 is the assigned range for medium effect size.

\section{Results and Discussion}

The total participants were 116 FS Biology students over four academic years. All Foundation students were international students and were from 27 countries. Of the participants, 53 had completed their prior education with English as the language of instruction while the remaining 63 had other languages as the language of instruction. The effect of the language of instruction of prior education on academic achievement scores on TTL and PBL was measured by the effect size calculation. The results are given in Table 1.

Students who had completed their prior education in English seemed to score higher than students who had other languages as the medium of prior education, showing that language difficulties might have affected the academic performance in Biology in both TTL and PBL. The difference in mean scores was greater on PBL than on TTL. The magnitude of difference was very small on both TTL (0.10) and small on PBL (0.20). This showed that students who had completed their prior education in non English speaking learning environment need more support in PBL. In TTL they might have got more support from the teachers in their learning process.

The magnitude of interaction between language of instruction used of prior education and learning traits was also measured by effect size calculation. The results are given in Table 2.

The magnitude of interaction with the introvert/extrovert traits was small (0.15) on TTL due to the very small (0.05) effect size of the difference in means between introverts with English and other languages of instruction and the small (0.20) effect size of the extroverts with English and other languages of instruction. On PBL there was a medium (0.65) interaction between language of instruction and the introvert/extrovert learning traits obtained from a very small (0.05) but reversed effect size of the difference in means between introverts with English and other languages of instruction and a medium (0.60) effect size of the corresponding difference among the extroverts. Thus the analysis of interaction between language of instruction of prior education and learning traits indicated that the introvert/extrovert traits clearly had some interaction with the language of instruction. The difference in performance between the two groups was more pronounced among the extrovert students, the introverts seeming to cope better.

A small (0.38) interaction was observed between language of instruction and intuitive/sensing traits on TTL, owing to the very small (0.12) but reversed effect size of the difference in means between the intuitive students 
with English and other languages of instruction compared to the small $(0.26)$ effect size of the difference in means between the sensing students with English and other languages of instruction. On PBL, the magnitude of interaction was small (0.18) obtained from a very small (0.09) effect size and a small (0.27) effect size of the difference in means between the two groups. Hence in the case of the intuitive/sensing traits it was seen that the intuitive students with other languages of instruction of their prior education seemed to cope better on TTL where as it was the sensing students with English as the language of instruction performed better on PBL. Hence intuitive/sensing traits had very clear interaction with language of instruction of prior education.

A very small (0.12) interaction was observed between language of instruction and thinking/feeling traits on TTL, owing to the small (0.16) effect size of the difference in means between the thinking students with English and other languages of instruction and the very small (0.04) effect size of the difference in means between the feeling students with English and other languages of instruction. On PBL, the magnitude of interaction was very small (0.07) obtained from a small (0.16) effect size and a small (0.23) effect size of the difference in means between the two groups. Thus the thinking/feeling traits did not seem to interact much with language of instruction. However, the very slight difference was in favour of thinkers who appeared better able to overcome any difficulties in language proficiency.

The perceiving/judging trait on the other hand had a very definite interaction with language of instruction of prior education. The magnitude of interaction between language of instruction and the perceiving/judging traits on TTL was large (0.78) owing to the small (0.42) but reversed effect size of the difference in means between the perceiving students with English and other languages of instruction and the small (0.36) effect size of the difference in means between the judging students with English and other languages of instruction. On PBL the magnitude of interaction was large (1.18) due to the medium (0.66) but reversed and the medium (0.52) effect sizes of the difference in means between perceiving students with English and other languages of instruction and judging students with English and other languages of instruction. Thus the general trend was reversed in the case of perceivers on both assessments in that among the perceivers, students with other languages of instruction scored higher than students with English as language of instruction. On the other hand among judgers, the reverse was the case on both assessments. This showed that the perceivers seemed to cope better with any language related difficulties.

\section{Summary}

This research study investigated international students' magnitude of difference in academic achievement scores and the magnitude of interaction between language of instruction of prior education and learning traits under two different methods of teaching and learning. The effects were measured by effect size calculations. The magnitude of difference in academic achievement scores was found to be very small on TTL and small PBL. The interaction between language of instruction of prior education and learning traits was found to be varied from very small to large in two different teaching and learning practices. International students often have languages other than English as language of instruction in their prior education. Comparisons between the performance of students with English as the language of instruction of their prior qualification and their counterparts with other languages of instruction, have shown that the difference in performance between the two groups was greater in PBL, although the difference was small. Hence it is recommended that students from other language backgrounds who have completed their education in other languages might need more facilitation to overcome their language difficulties in self-directed, student-centred PBL activities. Further interaction analysis showed that extroverts with other languages of instruction need more support under both methods of learning. Sensing students with other languages of instruction seemed to need more support on both TTL and PBL. Another interesting observation was that perceiving students with other languages of instruction actually scored higher than their counterparts with English as language of instruction reversing the general trend on both assessments. This suggests that judging students with other languages of instruction need more support on language issues. Hence it is recommended that teachers should encourage extrovert, intuitive, sensing and judging students from other language backgrounds to use support facilities provided by most universities to improve their language, writing, presentation and communication skills.

\section{References}

Bennett, C. I. (1999). Comprehensive multicultural education. Boston: Allyn \& Bacon.

Coe, R. (2006). Effect size calculator,CEM Centre Durham University. Retrieved March 2, 2007 from http://www.cemcentre.org/File/CEM\%20Extra/EBE/EffectSizeCalculator.xls.

Cohen, J. (1969). Statistical power analysis for the behavioral sciences. New York: Academic Press. 
Cohen, J. (1988). Stastistical power analysis for the behavioral sciences. New Jersey: Lawrence Erlbaum Associates.

Duch, B. J. \& Norton, M. (1992). Teaching for cognitive growth. Teaching Excellence, 4(8), 1-2.

Felder, R. M. (1993). Reaching the second tier: Learning and teaching styles in college science education. Journal of College Science Teaching, 23(5), 286- 290.

Fraser, B. J. \& Tobin, K. G. (2001). International handbook of science education. Dordrecht, Netherlands: Kluwer Academic.

Glass, G. V., McGaw, B., \& Smith, M. L. (1981). Meta-analysis in social research. Beverly Hills, London: Sage Publishers.

Hedges, L. V. \& Olkin, I. (1985). Statistical methods for meta-analysis. London: Academic Press.

Izard, J. F. (2004). Best practice in assessment for learning. Paper presented at the Third Conference of the Association of Commonwealth Examinations and Accreditation Bodies on Redefining the roles of educational assessment, March 8-12, 2004, Nadi, Fiji: South Pacific Board for Educational Assessment.

Riding, R. (2005). Individual differences and educational performance. Educational Psychology, 25(6), 659-672.

RMIT. (2006). Foundation Studies: Course Information Melbourne: RMIT Printing.

Shindler, J. (2002). Exploring various structural options for performance assessment scale design: Which rubric is best? National Forum of Teacher Education Journal, 12(2), 3-12.

Varughese, V. K. \& Fehring, H. (2009). Effects of students' approaches to learning on performance in two pedagogical environments. International Education Studies,2(4), 10-14

Yeung, A. \& Read, J. (2006). Are learning styles important when teaching chemistry? Sydney: School of Chemistry, University of Sydney.

Yeung, A., Read, J. \& Schmid, S. (2005). Students' learning styles and academic performance in first year chemistry. Sydney, Australia: The University of Sydney.

Table 1. Magnitude of difference of academic achievement scores under TTL and PBL by the language of instruction of prior education

\begin{tabular}{lllllll}
\hline $\begin{array}{c}\text { Teaching } \\
\begin{array}{c}\text { Learning } \\
\text { practice }\end{array}\end{array}$ & $\begin{array}{l}\text { Language } \\
\text { of } \\
\text { instruction }\end{array}$ & $\mathrm{n}$ & Mean & $\begin{array}{c}\text { Diff in } \\
\text { Means }\end{array}$ & $\begin{array}{c}\text { Effect size } \\
\text { of difference }\end{array}$ & $\begin{array}{c}\text { Magnitude } \\
\text { of interaction }\end{array}$ \\
\hline TTL & English & 53 & 35.86 & 1.19 & 0.10 & very small \\
& Other & 63 & 34.67 & & & small \\
PBL & English & 53 & 36.08 & 2.55 & 0.20 & \\
& Other & 63 & 33.53 & & & \\
\hline
\end{tabular}


Table 2. Magnitude of interaction between language of instruction of prior education and learning traits on students' academic achievement scores under TTL and PBL

\begin{tabular}{|c|c|c|c|c|c|}
\hline $\begin{array}{c}\text { Teaching } \\
\& \\
\text { Learning }\end{array}$ & Group 1 & Group 2 & $\begin{array}{l}\text { Effect } \\
\text { size }\end{array}$ & $\begin{array}{l}\text { Difference in } \\
\text { effect size }\end{array}$ & $\begin{array}{l}\text { Magnitude of } \\
\text { interaction }\end{array}$ \\
\hline TTL & $\begin{array}{l}\text { Eng Intro } \\
\text { Eng Extro }\end{array}$ & $\begin{array}{l}\text { Other Intro } \\
\text { Other Extro }\end{array}$ & $\begin{array}{l}0.05 \\
0.20\end{array}$ & 0.15 in favour of Extro & Small \\
\hline PBL & $\begin{array}{l}\text { Other Intro } \\
\text { Eng Extro }\end{array}$ & $\begin{array}{l}\text { Eng Intro } \\
\text { Other Extro }\end{array}$ & $\begin{array}{l}0.05 \\
0.60\end{array}$ & 0.65 by reverse trends & Medium \\
\hline TTL & $\begin{array}{l}\text { Other Inuit } \\
\text { Eng Sens } \\
\text { Eng Inuit } \\
\text { Eng Sens }\end{array}$ & $\begin{array}{l}\text { Eng Intuit } \\
\text { Other Sens } \\
\text { Other Intuit } \\
\text { Other Sens }\end{array}$ & $\begin{array}{l}0.12 \\
0.26 \\
0.09 \\
0.27\end{array}$ & $\begin{array}{l}0.38 \text { by reversed trends } \\
0.18 \text { in favour of Sens }\end{array}$ & Small \\
\hline TTL & $\begin{array}{l}\text { Eng Think } \\
\text { Eng Feel } \\
\text { Eng Think } \\
\text { Eng Feel }\end{array}$ & $\begin{array}{l}\text { Other Think } \\
\text { Other Feel } \\
\text { Other Think } \\
\text { other Feel }\end{array}$ & $\begin{array}{l}0.16 \\
0.04 \\
0.16 \\
0.23\end{array}$ & 0.12 in favour of Think & $\begin{array}{l}\text { Very Small } \\
\text { Very Small }\end{array}$ \\
\hline TTL & $\begin{array}{l}\text { Other Perc } \\
\text { Eng Judg } \\
\text { Other Perc }\end{array}$ & $\begin{array}{l}\text { Eng Perc } \\
\text { Other Judg } \\
\text { Eng Perc }\end{array}$ & $\begin{array}{l}0.42 \\
0.36 \\
0.66\end{array}$ & 0.78 by reverse trends & Medium \\
\hline & Eng Judg & Other Judg & 0.52 & 1.18 by reverse trends & Large \\
\hline
\end{tabular}

